\title{
ORÍGENES, FUENTES Y PRINCIPIOS JURÍDICOS DEL MATRIMONIO CIVIL EN EL PERÚ DE HOY: LO ROMANO, LO CRISTIANO Y LO GERMÁNICO
}

Róger RodRíguez ITURRI

Con toda probabilidad, el derecho como ciencia ha sido el más grande aporte que Roma ha dado a la humanidad. Mas Roma en su proceso de expansión y de diversificación geográfica anclará también raíces culturales en la antigua España. Lo propio ocurrirá con los bárbaros visigodos que, comandados por Ataúlfo, recorrerán Italia, las Galias, Francia, para involucrarse en la historia de la península ibérica, la que recibirá —durante 800 años-, desde Tarik, la influencia árabe. Al lado, empero, el elemento cristiano tendrá también un protagonismo determinante.

Visto así, presentemos, a propósito del matrimonio, la incidencia de los elementos romano, cristiano y bárbaro germano.

\section{Estructura jurídica del matrimonio romano}

Las fuentes romanas nos presentan nociones conceptuales sobre matrimonio.

Modestino definía el matrimonio: «Nuptiae sunt coniunctio maris et feminae et consortium pmnis vitae divini el humani iuris comunicatio» ${ }^{\perp}$. Señalaba Modestino que «el matrimonio es la unión del hombre y la mujer para vivir en consorcio y en plena comunión según el derecho divino y humano».

I IGLESIAS, Juan. Derecho Romano. Instituciones del Derecho Privádo. Barcelona, Editorial Ariel, 1982; p. 40 y sgts. 
Por su parte, Justiniano en las Institutas (538 d. J.) explic6: «Nuptiae autem sive matrimonium est viri et mulieris coniunctio individuam vitae consuetudiem continens» ${ }^{2}$. Con lo que señaló que: «Las nupcias son la unión entre el hombre y la mujer con la intención de continuar la vida en común...»*.

Sobre los elementos constitutivos del matrimonio romano se ha discutido bastante. Empero, nadie soslaya hoy la relievancia del consentimiento como característica propia del matrimonio romano.

Así, el matrimonio romano pervivirá en tanto exista el consentimiento. Es este elemento subjetivo, llamado también affectlo maritalis, su elemento capital. El matrimonio romano es «más bien un estado de voluntad cotidiano» ${ }^{3}$. Se requiere de un consentimiento continuo y duradero. De otro lado, tal matrimonio no está sujeto a formalidad jurídica alguna, lo que lleva a algunos autores a la convicción de que el matrimonio romano «consiste sólo en el consentimiento» ${ }^{4}$.

El matrimonio romano era jurídicamente informal en su esencia; hubo más bien formas rituales, de índole social o religiosa que pudieron acompañarlo. Ello provocó muchas veces la presencia de solemnidades de tipo religioso o mágico, pero éstas se ubicaron más en lo referente a lo social y lo religioso, y no tocaron la estructura jurídica propiamente dicha ${ }^{5}$.

Sin embargo, el verdadero instrumento probatorio del consentimiento matrimonial resultaba ser la propia convivencia marital. Ello ha llevado a algunos autores, dada la importancia que la convivencia conyugal adquiere en el romanismo, a considerar que es éste el elemento objetivo del matrimo-

2 HERNÁNDEZ TEJERO, Francisco. Derecho Romano. Madrid, 1959; p. 411.

* Como sabemos, Justiniano había compilado el derecho en un solo cuerpo, el Corpus Iuris Civilis, en el que se contenian las Instituciones, el Digesto, el Codex y las Novelas (533-548 d. J.).

3 ARIAS, J. y ARIAS BOART, J. A. Derecho Romano. Madrid, Editorial Revista de Derecho Privado, 1986; tomo II; p. 757.

4 ROBLEDE, Olis. El Matrimonio en el Derecho Romano. Roma, Editorial Roma. Universita Gregoriana, 1970; p. 90.

5 JORS, Paul. Derecho Privado Romano. Barcelona, Editorial Labor, 1937; p. 385 . 
nio, pues la convivencia tenía para ellos un auténtico sentido ético. La convivencia podía no ser efectiva y el matrimonio, empero, podía seguir subsistiendo, en tanto varón y mujer, ambos, se guardaran recíprocamente el respeto y la consideración: ello constituía el honor matrimonii.

Resultó tan evidente la importancia de la convivencia y su sentido ético, que inclusive podía llegarse a contraer matrimonio en ausencia del marido, por el hecho de entrar la mujer en la casa del varón mediante la deductio in domun mariti ${ }^{6}$.

¿Mas cuáles eran los requisitos para contraer válidamente matrimonio entre los romanos?

Según Ulpiano, cuando existía derecho para el matrimonio; si es que mediaba el consentimiento matrimonial; y si se era apto para procrear dentro del matrimonio?.

Pero para tener derecho matrimonial resultaba imprescindible ser ciudadano romano. Ellos, los ciudadanos romanos, además de los latini deteres (habitantes de condición intermedia entre ciudadano y peregrino), eran los únicos que poseían el connubium. Había entonces que ostentar el status libertatis y el status civitatis; era imprescindible gozar de la capacidad jurídica que permitiese exhibir el carácter de libertario y de ciudadano.

E importante como lo primero, indispensable, resultaba la aceptación matrimonial, y en los casos en que los contrayentes fueran alieni iuris (sometidos a la patria potestad de otra persona), eran los padres los llamados a prestar tal consentimiento. Establecido estaba que el varón tenía capacidad natural a los 14 años y que la mujer gozaba de ella a los 12 , y a partir de esas edades, varón y mujer podían contraer matrimonio.

En correlato directo a lo dicho, a propósito del consentimiento de los padres, el derecho romano afirmó que el silencio de ellos implicaba la aceptación matrimonial, y en el supuesto de que el padre negara injustificadamente la autorización matrimonial, estaba en vigencia la lex iulia de

6 IGLESIAS, Juan. Op. cit.; p. 566.

7 HERNÁNDEZ TEJERO, Francisco. Op. cit.; p. 412. 
Maritandis Ordinibus de Augusto (año 18), en virtud de la cual el magistrado quedaba autorizado para intervenir.

Al lado de lo expuesto, y con tanta importancia, figuraba el requisito de gozar de la aptitud procreadora, fundamental dentro de la estructura matrimonial romanista.

Además de los requisitos señalados antes, el derecho romano fue creando una variedad de impedimentos a propósito de la unión marital. Dentro de los impedimentos para el matrimonio romano se encontró la clasificación de impedimentos relativos o prohibitivos (si se referían a determinados sujetos solamente...) y los absolutos (que prohibían el matrimonio de una persona con otra determinada) ${ }^{8}$.

Dentro de estas clasificaciones, el derecho romano exhibi6 como impedimentos el impedimento de vínculo; el plazo de 300 días de espera para la viuda a fin de evitar la turbatio sanguinis o partus que otro matrimonio contraído antes del plazo máximo de gestación podría originar; el voto de castidad; y la condición de infame para la binuba; el impedimento por parentesco de sangre y por afinidad; la relación de tutor y pupilo; del adúltero con su cómplice y el matrimonio con la raptada; la unión marital del magistrado con mujer de su provincia9. Con posterioridad, el propio derecho romano agregó una variada lista de impedimentos relativos, entre los que figuró el caso de los militares, el matrimonio de los senadores con las libertas o con mujeres de condicion inmoral (prohibiciones que fueron aprobadas por el propio Justiniano $)^{10}$; por igual, el impedimento para contraer matrimonio entre patricios y plebeyos, que fue derogado el año 445 a.J. por la Lex Canuleia $^{11}$, y así otros tantos impedimentos aprobados fueron con el tiempo desapareciendo.

Importante es señalar, a propósito de los impedimentos establecidos

8 RIZZY, Miguel. Tratado de Derecho Privado Romano. Buenos Aires, Editorial Argentina Arístides Quillet, 1936; p. 165.

9 BONFANTE, Pietro. Instituciones del Derecho Romano. Madrid, Editorial Reus, 1965 ; p. 183.

${ }^{10}$ IGLESIAS, Juan. Op. cit; p. 571.

11 ORTOLAN, M. Compendio del Derecho Romano. Buenos Aires, Editorial Atalaya, 1947; p. 43. 
por el emperador Augusto, que si algún matrimonio se contraía sin cumplir los requisitos señalados por la ley, tales nupcias mantenían su validez, pero no eran aceptadas como Matrimonium Secundum Legem Iuliam et Legem Papiam Poppaeam Contractum ${ }^{12}$.

Necesario es señalar dentro de la estructura jurídica del matrimonio romano, la importancia fundamental de la manus (mano). Para los romanos, la mano es el miembro que puede manifestar exteriormente el poder. Consecuentemente, la manus constituyó, de manera significativa, el poder del marido sobre la mujer ${ }^{13}$. Aunque desde el año 471 a. J. en la propia Ley de las 12 Tablas se encuentran disposiciones jurídicas que intentan menguar el poder del marido sobre la mujer, acentuándose tal actitud a fines de la república romana, y consolidándose el proceso con Gayo en el siglo II después de Cristo, es indiscutible la trascendencia de la institución de la manus dentro del contexto matrimonial romano.

Por ello, el matrimonio romano históricamente se dividió en dos grandes etapas, la de «Cum Manus», en la que la mujer ostentaba la calidad de hija de la familia del marido, y la posterior llamada matrimonio «Sine Manus», en la que la unión marital no implicaba perder la pertenencia a la familia de origen.

Los matrimonios cum manus, históricamente en Roma acaecieron marcados con tres tipos diferentes: la confarreatio, la coemptio y el usus, mediante los que se producía el traspaso de la mujer a la familia del marido, a través de la denominada conventio in manum.

La confarreatio fue en realidad una ceremonia religiosa solemne, permitida sólo para quienes ostentaban la clase de patricios. Se celebraba en un acto sagrado ante 10 testigos y en presencia del sacerdote de Júpiter, Flamen Dialis, y mediante esta ceremonia se simbolizaba la unión marital. Parece tener su origen en una formalidad etrusca, y, por él, varón y mujer quedaban asociados en el mismo culto al entrar la mujer a participar en la religión del marido ${ }^{14}$.

12 IJORS, Paul. Op. cit.; p. 391.

13 VON IHERING, Rudolph. Espíritu del Derecho Romano. Buenos Aires, Revista de Occidente, 1947 ; p. 289.

${ }^{14}$ DE COULANGES, Fustel. La Ciudad Antigua. México, Editorial Porrúa, $1983 ;$ p. 30. 
Una segunda forma que podemos narrar la constituyó la coemptio, de origen antiquísimo, dado que el concepto en que se basa resultó común a los diversos pueblos indoeuropeos. Estaba constituido por una ceremonia simbólica de mancipatio de la esposa, acto que ocurría en presencia de 5 testigos, y ocasión en que el esposo golpeaba una balanza con una moneda de cobre, recudusculum, moneda que entregaba luego al vendedor de la mujer, quien hasta ese momento ostentaba el poder sobre ella. Acto seguido, el varón preguntaba a la mujer si quería entrar a formar parte de su familia. Tal formalidad sirvió para determinar el objeto y las condiciones de la venta (lex mancipii), para distinguirla así de la simple mancipación.

Con el tiempo la coemptio cayó en desuso, y al fin de la república se le empleaba para fines no matrimoniales, y era usado por las mujeres sui iuris para salir de la pasada tutela agnaticia, y para otros fines ${ }^{15}$.

Pero bueno es advertir que tanto la confarreatio como la coemptio significaron matrimonios de naturaleza fundamentalmente social y religiosa, en los que tenía predominante importancia un hecho (sea social, sea religioso), el mismo que marcaba el inicio de la vida conyugal.

Con posterioridad a los dos tipos de matrimonios antes indicados, apareció la institución matrimonial del usus, que fue la forma menos solemne de contraer matrimonio, hasta fines de la república, en que se convirtió en la regla general. Así como en los derechos reales, junto a la mancipatio se dio la usucapion, así también la convivencia continuada durante un año de un varón con una mujer producía el efecto matrimonial. Empero, tal matrimonio se evitaba mediante la usurpatio trinoctii, por la que la mujer se alejaba tres noches consecutivas de la compañía del varón.

Pero los matrimonios por coemptio y por usus, se daban fundamentalmente para las relaciones maritales entre los plebeyos ${ }^{16}$.

Al frente de los matrimonios antes descritos, apareció históricamente en el derecho romano, con el tiempo, el llamado matrimonio sine manus. Fue un tipo matrimonial surgido durante la época de la república, y que con

15 JORS, Paul. Op. cit.; p. 394.

16 ORTOLAN, M. Op. cit.; p. 44. 
posterioridad se difundió tanto que a la postre puede ser considerado probablemente como el típico matrimonio romano.

Constituía una forma de unión libre, pero matrimonial, carente de formalidades jurídicas, y que no concedía ni irrogaba poder al marido sobre la mujer. Empero, la vigencia de la affectio maritalis diferenció esta institución del concubinato romano ${ }^{17}$.

Conviene ahora referirnos a un asunto polémico a propósito del matrimonio romano: su naturaleza jurídica.

Es un tema que ha sido motivo de seria discusion.

«... en todo el medioevo y luego en el seno de la escuela culta hasta el s. XIX por doctrina común... los romanos... tuvieron el matrimonio por un contrato..., en otras palabras, que el matrimonio surgía en virtud de un consentimiento con carácter contractualista, por considerársele cual acto inicial de voluntad del que se originaba un vínculo jurídico»" ${ }^{18}$.

Con el tiempo, y en la versión liderada por Glück, y en la posición establecida por Savigny, se afirmó que:

«... que los contratos pueden ser obligatorios o no obligatorios y el matrimonio... es de estos últimos» ${ }^{19}$.

Fue con Monenti que el pensamiento jurídico se atrevió a postular una tesis distinta a las mencionadas. Monenti partió de los elementos exigidos para la existencia del matrimonio:

«... (convivencia) y consentimiento aunque no fuese declarado expresamente... Un tal consentimiento no podía entenderse... como contractual... como creador de un vín-

${ }^{17}$ HERRERA PAULSEN, Darío. Derecho Romano. Lima, Tipo Offset Sesator, 1984; p. 40.

${ }^{18}$ ROBLEDE, Olis. Op. cit.; p. 72.

${ }^{19}$ Ibidem; p. 73. 
culo que pudiese ya existir independientemente de su causa... El matrimonio era considerado como haciéndolo y como hecho a la vez, en cada momento» ${ }^{20}$.

Si bien es cierto que la tesis antedicha ha sido la que comúnmente se aceptó para el matrimonio romano, hoy en día no se puede afirmar que la discusión en torno al matrimonio romano esté zanjada. Las corrientes doctrinarias se han dividido hasta en tres vertientes a propósito del tema.

Una primera, estima que el matrimonio es un acto jurídico, y dentro de esta afirmación lo conceptúa como un contrato.

«... el matrimonio nace de un contrato. Éste sólo exige que los esposos sean capaces de consentir y que su consentimiento sea serio y no simulado... El contrato de matrimonio no admite condiciones ni términos» ${ }^{21}$.

Apréciese acá la importancia que se otorga a la manifestación de voluntad, sin darle mayor importancia al carácter permanente del matrimonio, que fue el aspecto que caracterizó al consentimiento en la Roma antigua.

Empero, algunos autores, sin llegar a identificar esta figura jurídica con el contrato, hablan de un «pacto bilateral consensual que trae obligaciones y deberes recíprocos entre marido y mujer» ${ }^{22}$.

Una versión distinta sobre la naturaleza jurídica del matrimonio romano, es la que identifica el consentimiento existente en él con el que se da en los contratos de sociedad.

«... el consenso de los contrayentes... único elemento esencial en orden a la existencia del matrimonio, el cual viene así a parecerse a un contrato de sociedad surgiendo y persistiendo por la mera voluntad de los cónyuges $»^{23}$.

${ }^{20}$ Ibidem; p. 80.

${ }^{21}$ SERAFINI, Felipe. Instituciones del Derecho Romano. Madrid, Espasa Calpe, 1968; p. 271.

${ }^{22}$ RIZZY, Miguel. Op. cit; p. 166.

${ }^{23}$ ARIAS, J. y ARIAS BOART, J. A. Op. cit.; p. 752. 
Empero, a esta postura sería también aplicable la crítica basada en el carácter patrimonial de los contratos.

Finalmente, encontramos una tercera posición en materia de naturaleza jurídica del matrimonio. Hay quienes sostienen que se trata de:

«... una mera situación de convivencia de dos personas de distinto sexo, cuyo inicio no está marcado por exigencias de formalidad alguna del orden jurídico, manteniéndose por la 'affectio maritalis' o intención continua de vivir como marido y mujer... El matrimonio romano... es una relacion de hecho» ${ }^{24}$.

No se trataba, por lo tanto, se dice, de un acto jurídico, y por ello «no cabe estar sujeto a modalidad alguna» ${ }^{25}$, sino más bien era un «hecho social en el cual la ley tenía poco que ver... ${ }^{26}$.

\section{Estructura jurídica del matrimonio canónico}

Durante los primeros diez siglos de la era cristiana, fueron más bien compendios de leyes eclesiásticas los que eventualmente aparecieron, muchas veces elaborados por particulares, con el fin de recopilar el conjunto de leyes que aisladamente se dieron en los diversos concilios y por los romanos Pontífices.

A mediados del s. XII, aparecerá la denominada Concordia, obra otra vez de un particular, esta vez del monje Graciano, la que reunió un conjunto disperso de leyes, siendo conocidas históricamente como el "Decreto de Graciano». Éste constituye la primera parte de la gran colección de leyes de la Iglesia, y a ejemplo del Cuerpo de Derecho Civil de Justiniano, al interior de la Iglesia comenzo a denominarse Cuerpo de Derecho Canónico. Contuvo leyes que por casi dos siglos habían sido dadas al interior de la Iglesia.

24 Loc. cit.

${ }^{25}$ IGLESIAS, Juan. Instituciones de Derecho Romano. Barcelona, Editorial Ariel, 1951, tomo II; p. 154.

${ }^{26}$ BARRY, Nicholas. Introducción al Derecho Romano. Madrid, Editorial Civitas, 1937; p. 129. 
El referido Cuerpo, además de incluir el denominado Derecho Graciano, albergaba el Libro Extra de Gregorio IX, el Libro Sexto de Bonifacio III y Las Clementinas (es decir la colección de Clemente V promulgada por Juan XXII), las Extravagantes de Juan XXII y las Extravagantes Comunes de otros papas. Tal compendio constituye lo que se denomina el «Derecho Clásico» de la Iglesia.

Se afirma que a este «Cuerpo» del derecho de la Iglesia latina corresponde también el Syntagma de Cánones o «Cuerpo de cánones oriental» de la Iglesia griega.

Empero, la Iglesia constataba, sobre todo en los tiempos de la reforma católica, desde el mismo Concilio de Trento, cómo todo su gran bagaje jurídico constituía «un inmenso cúmulo de leyes amontonadas unas sobre otras», rodeándose el sistema de gran inseguridad, otras veces de inutilidad y lagunas, haciendo peligrar la disciplina de la propia Iglesia.

Es por ello que desde que se preparaba el Concilio Vaticano I, los obispos solicitaron que se publicara una única colección de leyes, para facilitar la comprensión de las leyes de la Iglesia y la mejor interpretación por parte de sus pastores. Como quiera que el pleno del trabajo no pudo realizarse durante el período conciliar, fue el papa Pío X, apenas al inicio de su pontificado, quien asumió la tarea proponiéndose reunir y reformar todas las leyes eclesiásticas, eligiéndose el método moderno de la codificación ${ }^{27}$.

Sin embargo, es preciso repetir con David:

«... (derecho romano), de acuerdo a cuyas normas había vivido la iglesia y sobre el que se había fundado el derecho canónico que, en definitiva, sólo había significado una actualización de aquél...» ${ }^{28}$.

De otro lado, y en materia de historia y estructura matrimonial religiosa, digamos que a inicios de la era cristiana el matrimonio de los cristianos

${ }^{27}$ CÓDIGO DE DERECHO CANÓNICO. Madrid, Biblioteca de autores cristianos, 1983. Prefacio.

28 DAVID, René. Los Grandes Sistemas Jurídicos Contemporáneos. Madrid, Aguilar S.A., 1973; p. 29. 
fue un asunto temporal, y quienes se casaban usaban los mismos procedimientos de los paganos. Y es en el s. III, con el cristianismo, que comenzó a arraigar la idea de protección hacia la mujer.

De pronto es entre los siglos IV y XI que comenzó a aparecer en occidente, al lado de las ceremonias familiares y civiles, la ceremonia eclesiástica del matrimonio, sin carácter obligatorio, y a la que se van incorporando rasgos y ritos de las diversas culturas. Las costumbres civiles se fueron convirtiendo en eclesiásticas. Las cosas, símbolos, actos jurídicos civiles, las arras, el anillo, la dote, los objetos y costumbres procedentes de las tribus germánicas, celtas, francas, lombardas y otras, pasaron a la liturgia de la Iglesia $^{29}$.

Ya Ignacio de Antioquía había recomendado que el matrimonio se celebrara ante el obispo, y también en tiempo de Tertuliano contraen los cristianos su unión ante la ecclesia y lo sellan con una bendición, aunque ello no signifique aún que exista un rito litúrgico propio ni que sea ineludible la presencia del obispo en la celebración del matrimonio.

La indisolubilidad del matrimonio cristiano, que, desde Pablo, tiene su más profunda motivación en su carácter de símbolo de la unión de Cristo con la Iglesia (Eph 5, 32; 1 Cor y. 10s.), es decididamente afirmada por la mayoría de los escritores del siglo III.

No por razones de orden ideológico, sino más bien históricas y políticas -debilitamiento del poder real en el siglo X- a comienzos del s. XI, en occidente, la Iglesia asume el pleno control de la jurisdicción en materia matrimonial. Pero ¿cuál es el elemento fundamental, esencial, que otorga validez al matrimonio?

«La manera concreta de concebir y de vivir el matrimonio era la resultante de un gran barullo de concepciones y de culturas. Estaba, ante todo, la concepción romana del consentimiento. Se conocían también las ideas germánicas, francas, góticas y celtas, que se centraban en la idea de tu-

${ }^{29}$ SCHILLBEECKX, Eduardo. El Matrimonio, Realidad Terrena y Misterio de Salvación. Salamanca, Sígueme, 1968; p. 244. 
tela (mundium). La ceremonia del matrimonio se veía como un traditio puellae, un traslado de la joven del poder paterno a la autoridad marital. Por último, aparecía la idea antigua, todavía en vigor en todos los pueblos, de que la unión no se realizaba verdaderamente más que por la cohabitación y el cumplimiento del acto carnal. En la edad media, estos tres sistemas jurídicos no estaban netamente separados, sino que se influían mutuamente. Aun cuando la Iglesia, después de grandes trabajos, llegó a introducir en los países germánicos y francos su punto de vista romano (consensus), sin embargo, se siguió considerando en estas regiones que el consentimiento estaba virtualmente presente en las costumbres particulares; sobre todo en la transferencia de la autoridad o en los festejos del principio de la cohabitación» ${ }^{30}$.

Por ello, a comienzos el siglo XII, Hugo de San Víctor, el primer escolástico que escribe un tratado del matrimonio, señala que el consentimiento se expresa no sólo por el diálogo, sino también por un gesto, por una actio rei «como se acostumbra». Y así se va acentuando la firme idea de que la esencia del matrimonio es el consentimiento, y se hace histórica en occidente la clásica sentencia de Ulpiano: «nuptias non concubitus, sev consensus facit» (las nupcias no están consumadas sin el consentimiento) ${ }^{31}$.

En el siglo XI la Iglesia se ha apartado del derecho profano respecto a la realización del matrimonio, para atenerse a su propio sistema. Ello deriva de la reforma cluniacense, que permite a la Iglesia romper con el derecho profano, y prepara, más bien, la vuelta a las ideas del cristianismo primitivo. Fue de gran importancia, entonces, el retorno al derecho romano que, por esa época, era estudiado en las fuentes por los glosadores de Bolonia. El retorno al derecho romano-eclesiástico traerá consigo el pleno reconocimiento del matrimonio consensual. El matrimonio se originará entonces por el acuerdo de voluntades de los novios. Tal acuerdo, sin embargo, tendrá una significación religiosa, puesto que lleva en sí la administración del sacra-

${ }^{30}$ Ibidem; p. 252.

31 MARZAL, Manuel M. Estudios sobre Religión Campesina. Lima, Fondo Editorial PUCP y CONCYTEC, 1988; p. 194. 
mento entre los cónyuges. San Alberto Magno dirá que «el sacramento consiste en el contrato mismo», a lo que agregará santo Tomás que el consentimiento constituye el sacramento, y que la bendición del sacerdote no es sino un sacramental. Empero, en el siglo XII la Iglesia se halla discutiendo la significación del coito con referencia a la conclusión del matrimonio, sin que en el derecho romano ni en el derecho germánico el coito haya tenido carácter decisivo para tal conclusión matrimonial. Pese a que el matrimonio no consumado no se consideraba aún como matrimonio, tal opinión no pudo triunfar plenamente.

A partir del siglo XII se entendio que el consentimiento sin forma daba lugar a un matrimonio válido cuando la voluntad de las partes estaba dirigida hacia la eficacia actual del matrimonio. Junto a esto, debía bastar la promesa o esponsales para la conclusión del matrimonio cuando la voluntad matrimonial había tomado efectividad mediante cópula carnalis. El resultado de todos estos planteamientos fueron las conclusiones de matrimonios secretos y la bigamia.

Por ello, el cuarto Concilio de Letrán, en 1215, intentó poner remedio a este estado de cosas. Se exigió de nuevo la conclusión del matrimonio ante el párroco y los testigos, introduciéndose las proclamas según el ejemplo francés; de todos modos el consentimiento sin forma conservó su eficacia creadora del matrimonio. El casamiento laico fue suprimido, aunque sin resultado pleno ${ }^{32}$.

Entre 1545 y 1563 , ocurrido el Concilio de Trento, éste significará una especial explicitación de la teología del matrimonio, como consecuencia de las doctrinas protestantes al respecto. En el Concilio de Trento la Iglesia proclama la sacramentalidad, la indisolubilidad, y ante los llamados matrimonios clandestinos, sin optar por ninguna opinión a propósito de la identificación o separabilidad del contrato y del sacramento, restablece el antiguo decreto Tametsi en el que señala la forma de contraer matrimonio prescrita en el cuarto Concilio de Letrán, declarando inválidos los matrimonios clandestinos $^{33}$. Aunque sabido es que algunos padres de la Iglesia, en pleno

${ }^{32}$ PLANITZ, Hans. Principios de Derecho Privado Germánico. Barcelona, Bosch Casa Edit., 1957; p. 294.

${ }^{33}$ FABREGA Y GRAU, Ángel. Historia de los Concilios Ecuménicos. Barcelona, Ed. Balmes, 1960. 
Concilio de Trento, defendieron la teoría de Melchor Cano, a propósito de la no identificación del contrato y el sacramento. Afirmaba éste que el contrato es la materia próxima del sacramento y la forma la bendición del sacerdote, quien es el ministro del sacramento. Por consiguiente, se agregaba que: «una unión contraída sin la bendición nupcial puede ser un matrimonio verdadero y válido entre cristianos, aunque no matrimonio sacramental. Los que se han casado en estas condiciones no necesitan sino pedir la bendición del sacerdote, la cual transformará su matrimonio en sacramento».

Así pues, en el Concilio de Trento se buscó dar respuesta a asuntos relativos a la sacramentalidad del matrimonio o a su carácter netamente natural, y se absolvió el asunto vinculado a la virginidad y a la continencia.

El Concilio, en su VII sesión declaró, finalmente, que el matrimonio es uno de los siete sacramentos de la ley de Dios; empero otros diversos temas a definirse también sobre el tema matrimonial, fueron derivados hasta la sesión XXIV, ocurrida el 11 de noviembre de 1563.

Es en esta sesión - sesión XXIV— en que los 227 padres conciliares reunidos promulgaron el Decreto Doctrinal de 12 Cánones y el Decreto Disciplinario de Reforma que declaró el matrimonio como natural, uno e indisoluble. En esta misma ocasión el Decreto Tametsi restableció la forma de contraer el matrimonio prescrita en el cuarto Concilio de Letrán de 1215.

Y es a propósito del primero de los 12 cánones del Decreto Doctrinal, que el Concilio de Trento declara que:

«Si alguien dice que el matrimonio no es verdadero y propiamente uno de los siete sacramentos de la ley evangélica, instituido por Jesucristo, sino que es invención de los hombres, introducido en la Iglesia y que no confiere la gracia, sea anatema».

Dentro del razonamiento eclesiástico se sostiene que el hecho de que la noción cristiana del matrimonio otorgue, como otorga, gran importancia a la libertad del hombre, ha llevado a éste a crear «su contrato» y «su ley»; empero - afirman - ello no debe derivar en negar que el matrimonio es una institución divina que necesita del sacramento para recibir ese algo sagrado que posee. El contrato requiere del sacramento, que no es sólo la 
bendición nupcial. El compromiso de los esposos de respetar la unidad, la permanencia y la indisolubilidad del vínculo conyugal, hace al sacramento, y éste es el que otorga la gracia a los esposos.

Dentro del fundamento eclesial, se sostiene que el matrimonio es un sacramento porque es imagen de la unión mística de Cristo y la Iglesia, porque es un signo sagrado que produce la gracia que es dada por Dios, a través del hombre que como ministro suyo actúa en su nombre y como testigo calificado. Así, Dios se sirve del sacramento para estrechar la unión indisoluble e infundir la gracia entre los hombres, permitiendo que los haga constantes y fieles en sus nuevas obligaciones, y que en la vida conyugal, como esposos, sean instrumentos de Dios para plasmar el cuerpo material de sus hijos. Así como Dios es el único que puede crear las almas, Él es sólo el único que puede producir esta gracia.

De otro lado, en el canon II del Decreto Doctrinal se afirmo el principio cristiano de la monogamia. Por esta razón se recuerda que se unen y se juntan en este vínculo dos, y se vuelven uno, y así ya no son dos sino uno en una carne. «El hombre se unirá a su mujer y serán los dos una sola carne. Lo que Dios, pues, juntó, el hombre no lo separe» ${ }^{34}$.

Es de tal manera que la Iglesia declara al matrimonio perpetuo, indisoluble y único. Como el matrimonio no viene del exterior, ni aun de una autoridad eclesiástica, se debe entender que ha sido instituido por obra divina, y que por lo tanto sus leyes no pueden estar sujetas al arbitrio de ningún hombre, ni siquiera al acuerdo contrario de los dos cónyuges, pues éste es único, inmutable e indisoluble; no es la Iglesia la que hace el matrimonio, pues Ella no le añade nada.

A propósito de la indisolubilidad matrimonial, con el tiempo, Pío XII, papa entre 1939 y 1958, sostendrá su conveniencia, porque ella sirve:

«para la mutua realización de sí, pues la continuidad y la entrega lenta, hacen descubrir nuevos valores en cada cónyuge. $Y$ para proteger la dignidad de la persona humana. El matrimonio es una institución divina que hasta en sus

${ }^{34}$ EVANGELIO DE JESÚS. Mateo 19,5-6. 
expresiones más íntimas es en extremo delicada. Si no fuese indisoluble, la vida en común correría peligro y permitiría que se diesen deseos egoístas de búsqueda de la propia satisfacción, sin atender a la dignidad personal, ni al honor del cónyuge. La dignidad del hombre y la mujer, sobre todo de ésta, no conoce mejor defensa y protección que la indisolubilidad del matrimonio. Hay que comprometer el porvenir».

Respecto a la naturaleza misma del matrimonio canónico esbocemos algunos conceptos.

Sin perjuicio de su carácter divino, por ser una institución divina por naturaleza, la voluntad de la pareja tiene una gran importancia, y el matrimonio no se realizará sin el libre consentimiento de ambos. Empero, una vez tomada la decisión de contraerlo, esta pareja se hallará sujeta a las leyes y propiedades esenciales de la naturaleza matrimonial.

El matrimonio para la Iglesia es una institución de derecho natural; es una institución también jurídica que organiza las relaciones entre varón y mujer, alcanzando su carácter in fieri que constituye el contrato legítimo entre un varón y mujer para producir una comunidad indisoluble de vida (el matrimonio in facto), y provocar una comunidad indisoluble, exclusiva y perpetua.

Así, el matrimonio importa un acuerdo bilateral, cuyo objeto material son los propios contrayentes y cuyo objeto formal será la comunidad de vida. Sus elementos esenciales no podrán ser variados por acuerdo o voluntad privada, pues éste es indivisible por su propia naturaleza.

«Las propiedades esenciales del matrimonio son la unidad, a la que se opone la poliandria y la poliginea, y la indisolubilidad que excluye la división del vínculo a no ser por causa de muerte» ${ }^{35}$.

${ }^{35}$ CHELODI, Juan. El Derecho Matrimonial. Barcelona, Editorial Bosch, 1959 ; p. 18. 
Ambas propiedades corresponden al ámbito del derecho natural, el que se protege con la forma.

Y decimos:

«El núcleo del derecho canónico matrimonial es la obligatoriedad de la forma, que Trento introdujo mediante el Decreto Tametsi... y que el Decreto Provida Sapientique Cura, y el Decreto Ne Temere, corroboraron y purificaron de las incertidumbres jurídicas... Según esto, los matrimonios en que al menos uno de los cónyuges es católico no son reconocidos como válidos en la Iglesia si no han sido contraídos ante el Obispo o Párroco competente, o ante un sacerdote o diácono con delegación recibida de ellos o, en determinados casos, ante un seglar con delegación y ante dos testigos» ${ }^{36}$.

Pero desde el punto de vista substantivo, de la Iglesia, es importante anotar que el matrimonio empieza con la conclusión del acuerdo entre varón y mujer, regulada canónicamente, fundándose su sacramentalidad en su institucionalidad suprapersonal e incluso prepersonal.

En este orden de ideas, y en este estado de la exposición, se puede señalar que principios básicos del matrimonio canónico fundamentalmente son: aquél que indica que se ha de realizar entre bautizados; otro que señala que los ministros del sacramento son los mismos esposos que se confieren y reciben el sacramento (el ministro del culto ejerce la función de tesis qualificatus); que la materia (mutua traditio) y la forma (recíproca aceptación) se contienen en el mismo consentimiento matrimonial; reservándose para el matrimonio el favor iuris que beneficia la unión marital, al favorecer la validez del matrimonio en caso de duda sobre éste.

Pero la única causa eficiente del matrimonio es el consentimiento, manifestado con validez jurídica, es decir expresado por personas libres de impedimento y en la forma legítimamente establecida.

${ }^{36}$ FLORES, S. M. Naturaleza Jurídica del Matrimonio Canónico. Lima, monografía inédita, PUC, 1992. 
Aunque en buena cuenta había sido trabajo de Pío X, la colección universal, exclusiva y auténtica, que significó el primer Código Canónico propio de la Iglesia, éste fue promulgado por su sucesor, Benedicto XV, el 27 de mayo de 1917, entrando en vigencia el 19 de mayo de 1918. 75 años después, el 25 de enero de 1983, aniversario del primer anuncio que dio el papa Juan XXIII sobre la revisión del código precedente, Juan Pablo II decretó la promulgación del nuevo Código Canónico.

Pero es indispensable acentuar acá aún algunos aspectos.

Así, resulta procedente afirmar que la tendencia del Código de 1917 estuvo marcadamente volcada sobre un concepto de matrimonio fundamentalmente entendido como un contrato entre hombre y mujer para engendrar hijos. En el nuevo texto de 1983 se ha tenido muy en cuenta, para este efecto, la doctrina del Vaticano II, de carácter fundamentalmente personal, en que el matrimonio es concebido como «una comunidad íntima de la vida y del amor conyugal, creada por Dios y regida por sus leyes, que se establece sobre la alianza de los cónyuges, es decir sobre su consentimiento irrevocable» ${ }^{37}$.

Preciso es señalar, y de manera expresa, cómo la legislación canónica vigente en la Iglesia ha renunciado explícitamente, en materia de matrimonio, a mencionar la expresión «contrato», reemplazándola por la de «alianza matrimonial» según el can. 1055 del Código vigente (aun cuando en los anteproyectos del Código parece figurar la expresión «pacto»), ya que la finalidad de la acción apostólica y evangelizadora de la Iglesia en el ámbito de lo matrimonial deberá dirigirse a lograr de los fieles llamados al matrimonio una «vivencia lo más rica posible de esa comunidad conyugal».

«La nueva legislación del matrimonio, aunque muy detallada, incluso demasiado (199 cánones), es más humana que la antigua por más que conserva algunas reglas anticuadas. Progreso notable: el nuevo derecho integra como elemento constitutivo del matrimonio la comunión de toda

${ }^{37}$ DÍAZ MORENO, José María. «El Matrimonio en el Nuevo Código de Derecho Canónico», Revista Encuentro. Lima, Centro de Proyección Cristiana, No. 27, 1983; p. 156. 
la vida, mientras que el antiguo derecho sobre el cuerpo del cónyuge en orden a actos aptos para la procreación. Esto quiere decir que uno no se casa ya en adelante solamente o primeramente para darse mutuamente el derecho de tener relaciones sexuales en orden a la procreación, sino para formar una intimidad de vida y una comunidad de amor que asumen ciertamente la generación y educación de los niños, pero al interior de un compartir la vida y de una comunión de los espíritus, de los corazones y de los cuerpos" ${ }^{38}$.

Quedan así, con una nueva visión, amalgamados los tres bienes del matrimonio de los que nos hablara san Agustín: el «bonum prolus o bien de la prole", entendido como el derecho a procrear y a educar cristianamente a la descendencia; el «bonum fidei o bien de la fidelidad», que consiste en el mutuo derecho a la exclusividad para el cumplimiento del débito conyugal por ambas partes, y el «bonum sacramenti o bien del sacramento», que implica la indisolubilidad del vínculo y la consiguiente comunidad de vida.

$\mathrm{Y}$ así como obviamente los fines matrimoniales nos interesan para el estudio de la institución, hay un aspecto de la mayor importancia concerniente a este trabajo: es el relativo al consentimiento y al criterio que sobre él adopta la nueva visión canónica en la Iglesia.

Respecto al consentimiento, resulta particularmente importante la regulación positiva de uno de los artículos de nulidad matrimonial, que ha sido materia de constante jurisprudencia en los últimos años. Se trata, a nuestro modo de entender, de uno de los artículos particularmente llamados a solucionar diversidad de casos de matrimonios fracasados irreversiblemente. El canon dice:

«1095: Son incapaces de contraer matrimonio:

1) quienes carecen de suficiente uso de razón.

2) quienes tienen un grave defecto de discreción de juicio

${ }^{38}$ HUG, Joseph. «El Nuevo Código de Derecho Canónico: lo que tiene de nuevo y lo que no ha cambiado», Revista Encuentro. Lima, Centro de Proyección Cristiana, No. 28, 1983-1984; p. 143. 
acerca de los derechos y deberes esenciales del matrimonio que mutuamente se han de dar y aceptar;

3) quienes no pueden asumir las obligaciones esenciales por causa de naturaleza psíquica».

Se trata pues de un artículo ciertamente difícil y de discutida elaboración, «... que no se ha fijado definitivamente sino hasta la última redacción (del Código)...» $»^{39}$. La doctrina, la jurisprudencia, tienen aquí definitivamente una tarea importante de investigación, de interpretación y aplicación para muchos casos de matrimonios, cierta e irreversiblemente fracasados, y cuyo fracaso estaba ya presente en el mismo momento de contraer el matrimonio.

Pero hay más. Hay asuntos concernientes al matrimonio y al derecho canónico, sobre los que la Iglesia mantiene latente su preocupación, y sobre los que con interés hemos investigado.

El Sínodo de Obispos sobre «La Familia Cristiana en el Mundo de Hoy", que se celebró desde el 26 de setiembre hasta el 25 de octubre de 1980 , al que concurrieron 216 padres sinodales, con voto, además de expertos, auditores, delegados de diversas Conferencias Episcopales, representantes de iglesias orientales, superiores religiosos, prefectos de dicasterios y miembros sinodales nombrados por el papa Juan Pablo II, elabor6, a petición del propio papa, una serie que resultó ser de 43 proposiciones (no se acogió el pedido de cierto número de obispos - como por ejemplo los padres sinodales de Canadá- de que se publicaran las proposiciones, habiéndose conseguido limitada información posterior), a fin de que «tenga a bien (Su Santidad) en el momento que considere oportuno, presentar a la Iglesia Universal un documento sobre los cometidos de la familia cristiana, de la misma manera que ya lo hizo para la exhortación apostólica "Cateche si Tradendae" tras el Sínodo de 1977».

He aquí, y a propósito de los temas vitales que interesan a este estudio, las inquietudes de la Iglesia Universal respecto del matrimonio.

Por 201 votos a favor, 3 en contra, y 2 abstenciones, en la proposición 12, parte tercera, los obispos del mundo recomiendan al papa:

${ }^{39}$ DÍAZ MORENO, José María. Op. cit.; p. 157. 
«Que se aprecie el grado de madurez de fe y la conciencia que tienen los futuros esposos al hacer lo que hace la Iglesia. Esta intención requerida para la validez del sacramento no parece presente donde no existe, al menos, la intención mínima de creer también con la Iglesia, con su fe bautismal. Que se evite el rigorismo como igualmente el laxismo».

En la proposición 18 de los padres sinodales dirigida al Pontífice romano, con 194 votos aprobatorios, 6 contrarios y 6 abstenciones, éstos recomiendan que, además de que las Conferencias Episcopales de cada país puedan estudiar los elementos culturales que rodean el matrimonio y la familia en cada localidad, a fin de realizar una verdadera inculturación de la fe cristiana:

«Teniendo en cuenta la diversidad de las culturas y de las tradiciones, se concedan facultades a las Iglesias particulares y a las conferencias episcopales sobre todo en lo que concierne a la estimación concreta de valores y a la elaboración de normas relativas a la celebración y a la validez del matrimonio, tal como ha sido establecido en la introducción al ritual de la celebración del matrimonio $\left(\mathrm{N}^{\circ} .12\right.$, 16,17 y 18)».

Preocupados los padres sinodales respecto a la madurez necesaria para contraer matrimonio, éstos en la proposición 13, parte quinta, aprobada por 200 votos, con 4 abstenciones y 2 votos contrarios, recomendaron a Su Santidad que:

«En razón de la dignidad intrínseca del matrimonio, y en el momento en el cual se incrementa cada vez más el número de matrimonios destruidos y las declaraciones de nulidad, es urgente insistir sobre la instrucción y la formacion adecuada, de los futuros esposos, de forma que puedan reconocer la permanencia de la unión sacramental, y contraer matrimonio con la madurez necesaria. Se pide apremiantemente a las Conferencias Episcopales introduzcan modalidades de matrimonio que permitan a los futuros esposos adquirir conciencia más clara de la gravedad de 
su decisión; y a los pastores que se aseguren de la disposición adecuada de los futuros esposos»*.

De lo presentado y expuesto, más que manifiesto, evidente, se advierte la enorme preocupación de la Iglesia sobre la importancia de la madurez y conciencia en el consentimiento matrimonial, en vista de que éste es una auténtica causa eficiente que otorga al matrimonio validez canónica.

\section{Estructura jurídica del matrimonio germano}

A propósito de la influencia del cristianismo en la teoría jurídica y en la práctica del derecho privado alemán, Planitz sostiene que «... en materia de derecho de familia la ideología del cristianismo tuvo una fuerza directriz cada vez más intensa» ${ }^{40}$. Ello, obviamente, sin desconocer la influencia del derecho romano en la génesis propia del derecho germánico.

Pero no es posible entender culturalmente la Edad Media en la humanidad (476-1, 453 d. C.), sin el conocimiento de los factores bárbaro, cristiano y romano en la historia.

Los sentimientos de nobleza, de independencia, de fidelidad personal, la caballerosidad y el espíritu guerrero, el orgullo señorial y la defensa del honor personal, fueron frutos con los que contribuyó la cultura bárbara para el medioevo.

Con ellos estuvo vigente el aporte del cristianismo, con su hondo sentido espiritual, moral, humano y religioso en la comprensión de Dios y del hombre.

Las ideas del romanismo también invadieron el medioevo, y la mayoría de los reinos, futuras naciones europeas, formáronse en las regiones que antes habían pertenecido al Imperio romano de occidente. Ellas, y el mun-

* La información relativa a las proposiciones del Sínodo de los Obispos al Santo Padre sobre la Familia, ha sido hallada en la revista francesa Documentation Catholique, de 7 de junio de 1981, Francia.

40 PLANITZ, Hans. Op. cit.; p. 5. 
do en buena parte, heredaron no sólo la importancia del idioma latino, el concepto de la vida urbana, un cúmulo de costumbres, el arte y la religión, sino principalmente con su organización municipal o comunal, el derecho, quién sabe la contribución más esplendorosa que la cultura romana haya dado a la comunidad universal.

Volviendo a la propia cultura germánica, para ellos la palabra «alemán» aparece por primera vez hacia el siglo VIII, y en un primer momento sólo sirvió para explicar el idioma que se hablaba en la parte oriental del Imperio franco. Este imperio alcanzó su máximo esplendor con Carlo Magno, nieto de Carlos Martel e hijo de Pipino el Breve, el que en sus 48 años de gobierno logró expandir el territorio de su reino, reuniendo pueblos de diversas razas y credos en un solo imperio, bajo una competente organización y administración. A la muerte de Carlo Magno, el año 814 d. C., a la edad de 72 años, le sucedió su hijo Ludovico Pío, quien incapaz de dirigir los destinos de los vastos dominios dividió el imperio entre sus hijos Lotario, Pipino y Luis, concediendo posteriormente derechos a sus propios descendientes, Carlos El Calvo (adjudicándole el territorio del oeste, es decir el reino de Francia); a Luis (a quien entregó los territorios del lado derecho del río Rhin, la Germania, o sea la actual Alemania); y a Lotario (a quien concedió Latoringia, es decir Italia y una parte de la Galia).

Fue así como surgieron dos imperios, uno en el este y otro en el oeste, cuyos límites coincidían aproximadamente con la división entre el idioma alemán y el francés. Pero paulatinamente se fue desarrollando en el lado oriental un sentimiento de pertenencia a una propia comunidad, y la designación «alemán» comenzó a ser aplicada no sólo al idioma sino también a todas las personas que lo hablaban y finalmente al territorio que habitaban ${ }^{41}$.

En todo este territorio se dio un proceso propio para el derecho. Así, en materia familiar no se puede desconocer la presencia de una suerte de norma jurídica familiar desde la llamada época antigua, norma jurídica familiar desde un principio vinculada a la ética. En el derecho de familia se consagró por ello la tutela colectiva de la sippe y en ella la absoluta potestad del padre y el matrimonio forzoso. En esto no puede desconocerse la vigencia de ideas religiosas que influyeron en forma directa en el derecho privado.

${ }^{41}$ ROMER, Karl. La Realidad Alemana. Gütersich 1987, p. 45. 
En un momento, al lado de los principales valores germánicos tendría sin duda presencia la doctrina cristiana. Justamente la influencia de la Iglesia es la que provocará la disminución del poder de la sippe, al establecer impedimentos matrimoniales y al combatir al matrimonio forzoso.

Hacia el siglo XVIII en el derecho germánico se habrán desvanecido las últimas ataduras medievales, y la reforma y el derecho natural marcarán una sentida influencia en los aspectos familiares, advirtiéndose ello en la disolución del matrimonio concluido mediante contrato civil (derecho natural).

Pero la vigencia romanista en ningún momento dejará de marcar su presencia en el proceso del derecho germánico. En vista de que el derecho germánico hacia esta etapa es un derecho de las ciudades y no un derecho nacional, el camino para la recepción del derecho romano apenas sí podría encontrar obstáculos.

Ya en la época de Otón III, la codificación justinianea se consideraba parte del derecho imperial alemán; y la Escuela de los Glosadores de Bolonia (1100-1250) coronada por la Glossa Ordinaria de Accursius, había provocado mediante la interpretación de las fuentes un primer conocimiento del derecho romano. Este derecho sería luego adaptado por los posglosadores (1250-1500) a las necesidades de la vida germana medieval, y luego clasificado y ordenado en un sistema jurídico coherente, destacando la tarea de Bartolo de Sassoferrato y su discípulo Baldus de Ubaldis.

Sólo en el siglo XVIII, y para Alemania, por la influencia del derecho natural, se iniciaría la decadencia del derecho romano.

Pero vistas todas estas influencias jurídicas y culturales en el territorio germano, veamos ahora, y comprendamos mejor, lo que específicamente ocurrió con el matrimonio.

En la antigüedad, se afirma que los germanos vivieron en un régimen de matrimonio monogámico, por cuanto sólo a los nobles les estaba permitida la poligamia.

Planitz dice:

«El matrimonio era una comunidad de vida plena y durade- 
ra, y para los germanos tenía además carácter divino, puesto que en ella se consumaba la renovación de la Sippe. El marido gozaba del munt, o potestad sobre su mujer; un matrimonio sin munt no tenía lugar entre los germanos» ${ }^{42}$.

Según lo expresa el propio Planitz, los menores de edad no eran capaces de autodeterminaciones; en consecuencia, por ellos decidían sus padres, y de no existir éstos, sus tutores ${ }^{43}$.

Probablemente como en todas las culturas, el matrimonio germánico tuvo un proceso evolutivo.

El primer dato que nos da la historia cultural y jurídica es la presencia del matrimonio por contrato. Por el contrato de matrimonio se enlazaban maritalmente un varón y una mujer, empero en verdad se enlazaban con ellos también dos sippen, que eran las familias a las que pertenecían los futuros cónyuges. El novio representaba por sí a su propia sippe, en tanto que la novia era representada por su pariente más próximo, el mismo que debía ostentar el munt (poder o potestad) sobre ella. En realidad el consentimiento de la novia no constituía un elemento jurídico gravitante, aunque en algunas circunstancias fue tenido en cuenta.

La estructura jurídica interior del matrimonio por contrato consistía en una primera petición (werbung) con la que tenía lugar los esponsales, o la promesa de casamiento (verlobung), promesa por la cual el novio se obligaba al matrimonio, y el receptor de la promesa a la entrega de la-novia. Este acto era acompañado de la entrega de regalos en favor de la sippe de la novia.

El enlace matrimonial propiamente provocaba la comunidad de mesa $\mathrm{y}$ de afinidad entre las sippen que quedaban vinculadas.

«Ante los parientes reunidos eran examinados los regalos o dádivas y la novia era entregada al novio; esta entrega de la novia era la trauung... el novio, estando armado, to-

42 PLANITZ, Hans. Op. cit.; p. 289.

43 Ibidem; p. 334. 
maba de la mano a la novia y la colocaba sobre sus rodillas; de esta manera adquiría el munt o potestad sobre su mujer. Después de esto se realizaba la conducción a la casa del novio, acto que recibía el nombre de carrera de la novia (brautlauf). La mujer cambiaba de hogar, de puesto en los antepasados de la Sippe. A continuación, los cónyuges, en presencia de testigos, pasaban al lecho nupcial $»^{44}$.

Empero, en el período franco se acentuó el carácter contractual del matrimonio, pero esta vez derivado a la compra (uxorem emere). Tal contrato tenía un proceso interior. Un matrimonio por compra sólo era eficaz si había sido contraído públicamente mediante desponsatio (verlobung), y posterior entrega de la novia por los parientes (trauung). En el territorio galo la desponsatio se configuró como una suerte de contrato con arras, en el que el novio pagaba a quien ostentaba el munt sobre la novia, unas arras. Posteriormente la rigidez del mencionado contrato se sustituyó por el llamado vadiado (wettvertrag), que era un contrato de deuda, y que se configuraba con la entrega de una varita que era el precio de compra de la novia - wittum-, comprometiéndose a su vez el que ostentaba sobre ella el munt a la entrega de la pretendida, y al deber de proporcionar al novio la potestad que él venía ejerciendo. Con el tiempo, el wittum le sería entregado directamente a la novia.

El matrimonio por rapto es la segunda expresión histórica, cultural y jurídica del matrimonio germánico. Paralelo al matrimonio contractual o matrimonio por contrato que hemos narrado, se reconoció también entre las costumbres germanas el matrimonio por rapto (entführungsehe). $Y$ es que cuando no se lograba el consentimiento de la sippe para contraer matrimonio con la novia, el novio podía convertir a su amada en su mujer raptándola, pero necesariamente con su anuencia, y en la presencia de un mediador o testigo, que era quien entregaba a la novia. De tal modo, la mujer dejaba de pertenecer a su original sippe, pero necesariamente el varón debía pagar a tal sippe una busse. Cabe mencionar que no procedía el matrimonio por rapto sin la anuencia de la raptada, pues el robo de la mujer (frauenraub) estaba prohibido.

44 Ibidem; p. 290. 
Con el tiempo, y durante el período franco, el matrimonio por rapto sería severamente repudiado tanto por el Estado como por la Iglesia; empero, tal matrimonio se mantuvo largo tiempo como costumbre jurídica en la vida cultural germánica.

Pero advertido como está que en el matrimonio por compra y en el matrimonio por rapto latía la estructura jurídica del consentimiento, no tardó en aparecer dentro del sistema jurídico germánico el llamado matrimonio consensual (konsensche), por el que se ofrecía a la mujer la posibilidad de hacer prevalecer o manifestar su voluntad en la elección de su marido. Es entonces cuando el munt comienza a tomar un rumbo distinto. Así, la mujer de una clase social superior contraía matrimonio con un varón, o en el caso de una noble con quien no lo era, y en tal unión marital no se producía el munt, en favor del marido.

La idea del consentimiento, que se fue desarrollando con todo este proceso, permitió también que tal consentimiento, para ambas partes, se comenzase a recabar en muchos casos de matrimonio con munt, y fue la Iglesia quien predicó que se tomase en consideración la voluntad de la novia. El matrimonio consensual se conservó durante toda la Edad Media, y aunque en algunos matrimonios con munt no fue considerado, repetimos, en otros muchos sí lo fue, pues el acuerdo de voluntades de los novios se convirtió en núcleo y esencia del contrato matrimonial germano, sin perjuicio de la trascendencia de la cohabitación o cópula matrimonial, que se consideró indispensable para producir los efectos patrimoniales del matrimonio*.

En los tiempos modernos la conclusión del matrimonio alemán descansa sobre la base del matrimonio civil. Ocurre ello a partir de la negación de la naturaleza sacramental del matrimonio en base al trabajo de difusión realizado por la Reforma, y la difusión del derecho natural que exigió la liberación de la vida estatal de la mediatización eclesiástica medieval.

Sin embargo, el proceso de secularización del matrimonio en Alema-

* Pero debe advertirse que la Iglesia, al igual que la época imperial posterior, repudió en principio el matrimonio de consentimiento o simple matrimonio consensual, por entender que iba contra el mandamiento de incondicional sumisión a los padres; consecuentemente derívese de este planteamiento la importancia y trascendencia del consentimiento de los padres para el matrimonio de sus hijos. 
nia ha sido lento. Así es que entonces el matrimonio civil ha alcanzado dos formas. En principio sólo se admitió como matrimonio civil el facultativo, pero existirá a su lado el matrimonio civil necesario, particularmente para los disidentes católicos y los judíos.

Hoy, en Alemania, en materia matrimonial, lo decisivo y determinante es el contrato formal de los prometidos ${ }^{45}$.

${ }^{45}$ Ibidem; p. 297. 